Advances in Geosciences, 3, 41-46, 2005

SRef-ID: $1680-7359 /$ adgeo/2005-3-41

European Geosciences Union

(c) 2005 Author(s). This work is licensed

under a Creative Commons License.

\title{
Role of the Radiophysical Research Institute (NIRFI) for promoting and teaching science in Russia
}

\author{
S. D. Snegirev, V. M. Fridman, and O. A. Sheiner \\ Radiophysical Research Institute, Nizhny Novgorod, Russia
}

Received: 31 August 2004 - Revised: 1 November 2004 - Accepted: 10 November 2004 - Published: 16 June 2005

\begin{abstract}
We present, how the Radiophysical Research Institute (NIRFI) has conducted work on the popularization of its scientific achievements in the areas of astronomy, solar physics, the Sun-Earth connection and associated geophysics.
\end{abstract}

\section{Introduction}

The knowledge of our environment is an integral part of the existence of humanity. In this case turning to outer space has always been the highest spiritual sphere of consciousness. Therefore it is important, that from the early years of development, not only to teach grade-appropriate knowledge about the structure and the characteristics of the surrounding space, but also to support that a continuing interest in the dynamic picture of the space environment and how one views humanity's home is maintained. The current level of audio and video technology and computer simulations makes it possible for us to do this in a captivating way, adapted readily for the age and educational level of the target audience.

The Radiophysical Research Institute of the Ministry of Education and Science (NIRFI) was founded in 1956 in Gorky, now Nizhny Novgorod. Since that time outreach efforts have been directed towards: 1) the popularization of the natural-sciences and astronomical knowledge, 2) the expansion of interest among the young generation in research work in such areas as astronomy, solar physics, the Sun-Earth connection and associated geophysics.

\section{NIRFI's activities}

Activities in the field of education, instruction, and training by the personnel at NIRFI and other institutes/universities in Nizhny Novgorod are presented in Table 1. The age groups

Correspondence to: O. A. Sheiner

(rfj@nirfi.sci-nnov.ru) targeted are listed as a function of the institutes/universities involved.

\subsection{Base knowledge of astronomy and junior children}

Beginning from the early ages (primary and junior schoolchildren), the staff of NIRFI try to inculcate in them an interest in the phenomena of the surrounding space. Naturally this is not difficult to do, due to the many exciting phenomena connected with space that exist, such as the motion of planets on the firmament, stars, solar and lunar eclipses. Special interest lies in phenomena directly connected with the subjugation of outer space by man.

NIRFI relies on the Nizhny Novgorod Planetarium, one of the best Russian establishments of this type, collaborating with the International Association of Planetariums. When invited, staff of NIRFI present lectures at the planetarium (for example, O. Sheiner, "What is space weather?"; V. Melnikov, "Contemporary base of experimental ground-based and space studies").

The staff of the institute constantly deal with the popularization of scientific knowledge.

Lev Erukhimov (Fig. 1) was engaged heavily in the teaching and promotion of physics among the very young people, as he called them "adults younger that 16 ".

Most vividly this appeared in a series of broadcasts on the Nizhny-Novgorod television by the name "Alone with the stars". This series, which existed almost four years, used contemporary video and audio to present the information in a story-tale manner about the main achievements of astrophysics, physics of outer space and near-Earth phenomena. In this program many scientists from NIRFI took part along with scientists from other research Russian institutes, including Noel Laureate Vitaly Ginzburg, - one of the NIRFI founders.

In a popular style and with a very good sense of humor Lev Erukhimov explained, for example, the effect of changing the frequency of the waves of the moving emitter or reflector of waves (L. Erukhimov, "Doppler effect, or from the 
Table 1. Education, instruction, and training activities by the personnel at NIRFI and other institutes/universities in Nizhny Novgorod.

\begin{tabular}{|c|c|c|}
\hline \multicolumn{2}{|c|}{ Age Group Targeted } & Institutes/Universities involved \\
\hline $\begin{array}{l}\text { Preschoolers } \\
\text { Junior schoolchildren }\end{array}$ & $5-10$ years old & $\begin{array}{l}\text { - NIRFI } \\
\text { - Planetarium }\end{array}$ \\
\hline Older schoolchildren & $10-16$ years old & $\begin{array}{l}\text { - NIRFI } \\
\text { - Planetarium } \\
\text { - Center of the Aerospace Education }\end{array}$ \\
\hline University first-year students & 16-19 years old & $\begin{array}{l}\text { - NIRFI } \\
\text { - Pedagogical University } \\
\text { - Classical University } \\
\text { - Technical University } \\
\text { - Center of the Aerospace Education }\end{array}$ \\
\hline University last-year students & 19-21 years old & $\begin{array}{l}\text { - NIRFI } \\
\text { - Classical University } \\
\text { - Pedagogical University } \\
\text { - Technical University }\end{array}$ \\
\hline
\end{tabular}

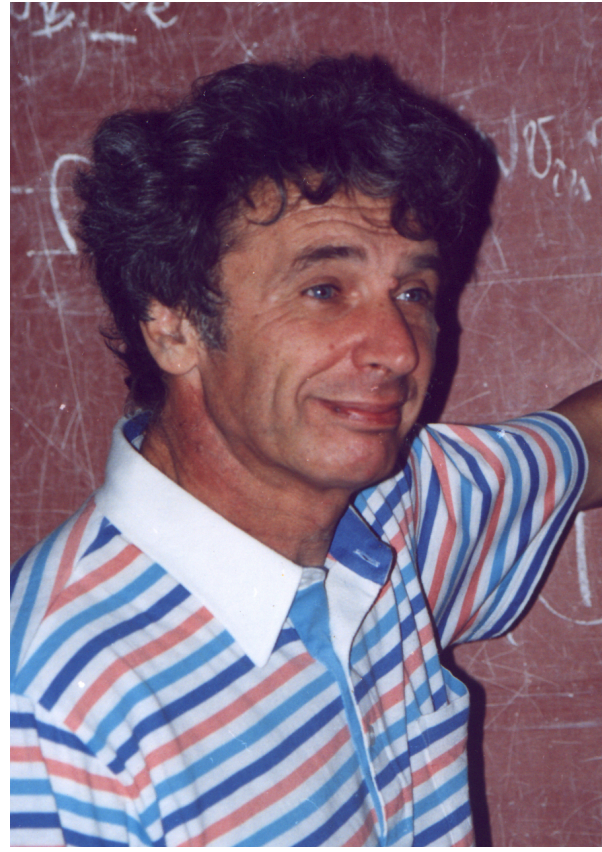

Fig. 1. Lev M. Erukhimov.

steam-locomotive whistles to color music of the Universe", see Fig. 2) or the nature and physics of waves in a plasma (L. Erukhimov, "The ionosphere as a space plasma laboratory", see Fig. 3).

\subsection{Developed activities and schoolchildren}

For enabling learning in the schools, we try to introduce children to the knowledge, which helps to reveal and to realize their abilities. Aid in this renders the Internet, which presents unlimited possibilities for the satisfaction of children's cu-

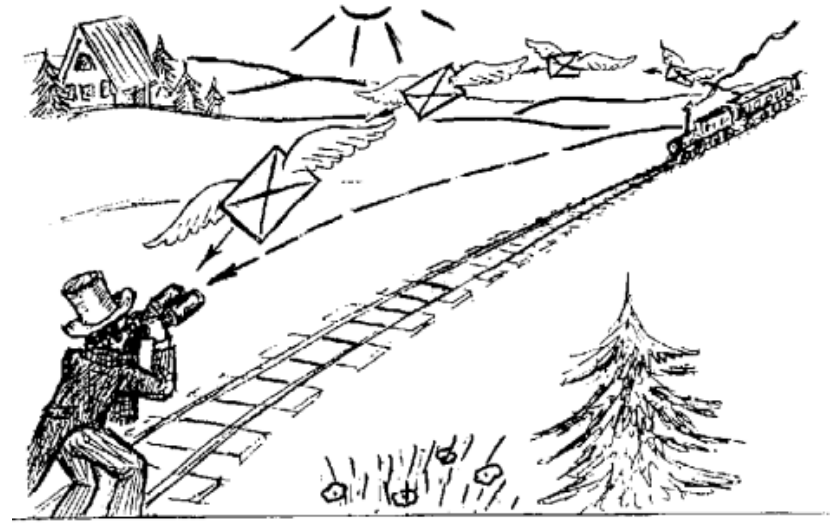

Fig. 2. Illustration of the Doppler effect.

riosity and the development of children's fantasy. However, it is important only to guide them in the search.

For this purpose, for example, colleague V. F. Mel'nikov showed, how it is possible to use actual solar data, obtained from contemporary automatic spacecraft (e.g., SOHO, GOES, RHESSI) practically in real-time and others, for organizing the studies through a virtual solar observatory at school. After presenting relevant Internet addresses, on which it is possible to obtain this information, NIRFI renders systematic aid conducting studies at schools. A detailed report about this was presented at the All-Russian conference "New technologies in the teaching of astronomy" (2-4 December 2003, Nizhny Novgorod).

It should be noted that the colleagues from NIRFI pay considerable attention to systematic questions related to the teaching of astronomy at schools (R. V. Troitsky, "Astrophysics in the school course of astronomy: how to find hours for teaching and why this is necessary"). 




Fig. 3. Waves in a plasma at different degrees of magnetization.

The colleagues of NIRFI have also repeatedly published in the yearly almanac "Astronomical calendar", produced by Nizhny-Novgorod Pedagogical University. The articles describe the basic phenomena of solar activity, the list of such basic events, the analysis of solar activity and the geophysical situation during the specific temporary periods. Thus, for instance, almanacs include the articles of V. M. Fridman, "Solar activity in 2000-2001", and V. N. Ishkov and V. M. Fridman, "Solar and geomagnetic situation in 2002-2003".

\subsection{Training-research activities and older schoolchildren}

Basic work with the schoolchildren begins when they are in the upper classes, where they under the management of qualified colleagues begin to carry out training-research works on a specific selected theme.

They select a subject based on works conducted or planned at the institute, which substantially increases the interest of the children in their fulfillment. Then they perform intensified studies on the phenomena (e.g. physical processes involved) in respect to their training-research work. Scientists in this case adapt, as far as possible, the description of these phenomena to the level of knowledge that the children have from their school courses.

This method was acquired, planned and was expanded when the Center of the Aerospace Education was created in Nizhny Novgorod, an organization of which the colleagues of NIRFI took most part in (Lev Erukhimov and Victor Mel'nikov). Since that time Izabella Porus is director of the Center of the Aerospace Education.

The selection of children is conducted in many schools of the city and surrounding region with physics-mathematical specialization. The Institute offers working rooms and laboratories for conducting the studies, and scientists from NIRFI work in the context of this Center, offering their pedagogical know-how and scientific knowledge. Schoolchildren and

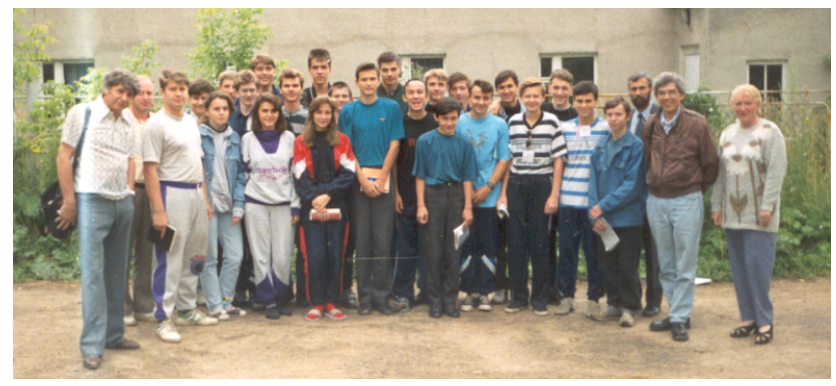

Fig. 4. Participants and lecturers at the Summer Session, out-oftown observatory NIRFI “Zimenki”.

students in first year university begin to participate in the scientific seminars of the institute as the "listeners".

\subsection{Summer programs}

A special part of the education for the schoolchildren and students of first year university is the summer session, arranged in the out-of-town observatory NIRFI "Zimenki” (Fig. 4).

For a period of two-three weeks the children live at the observatory, become acquainted with the work of the research laboratories, make practical laboratory works on observatory facilities and conclude their training-research works, carried out during the training year.

The daily works of the laboratory are based on projects such, as "Studying the ionosphere using the pulse vertical sounding method", "Monitoring the solar radio emission flux", "Determination of the passband and time constant of the radiometer", "Measurement of the radiation pattern of the parabolic antenna".

The chief scientists of Nizhny Novgorod give lectures for the students of the summer session. The summer session is completed by the students/older schoolchildren defending their executed training-research works as well as the astronomical and natural-science knowledge acquired during the training year. This exam is useful for the children for their future. The exam commission members are leading scientists from different research Institutes (NIRFI, IAP RAS) and Universities. The children's contact with them often have an influence on their future study and later work specialty selection.

Many of the training-research works have been entered in Russian competitions such, as 1. COSMOS, conducted with the participation of Moscow State Bauman Technical University (Moscow), 2. All-Russian competition-reading by memory Samuil Kaplan (Nizhny Novgorod), the scientific conference of the students in Kazan. More than 15 students, who carried out works under the scientific management of the colleagues of NIRFI have become prizewinners of these competitions.

Here are some examples of such training-research works: Men'kova Yulia - at the present moment - student at the Radiophysics department of Nizhny-Novgorod State University. The result of her work "About the correlation of the 


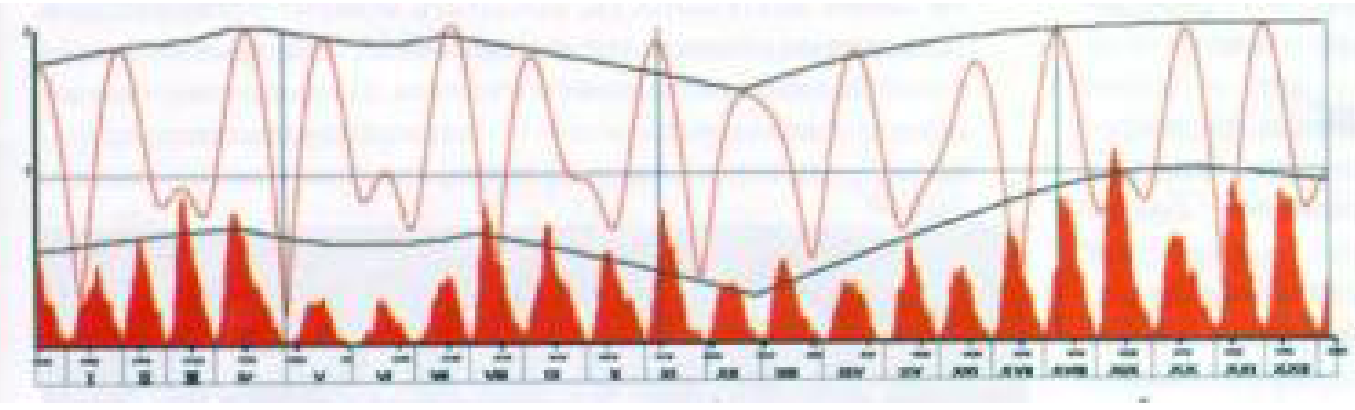

Fig. 5. The behavior of the distance between the center of the Sun and the Solar system (upper curve) and the corresponding Wolf Numbers (lower curve) during the years 1750-1999.
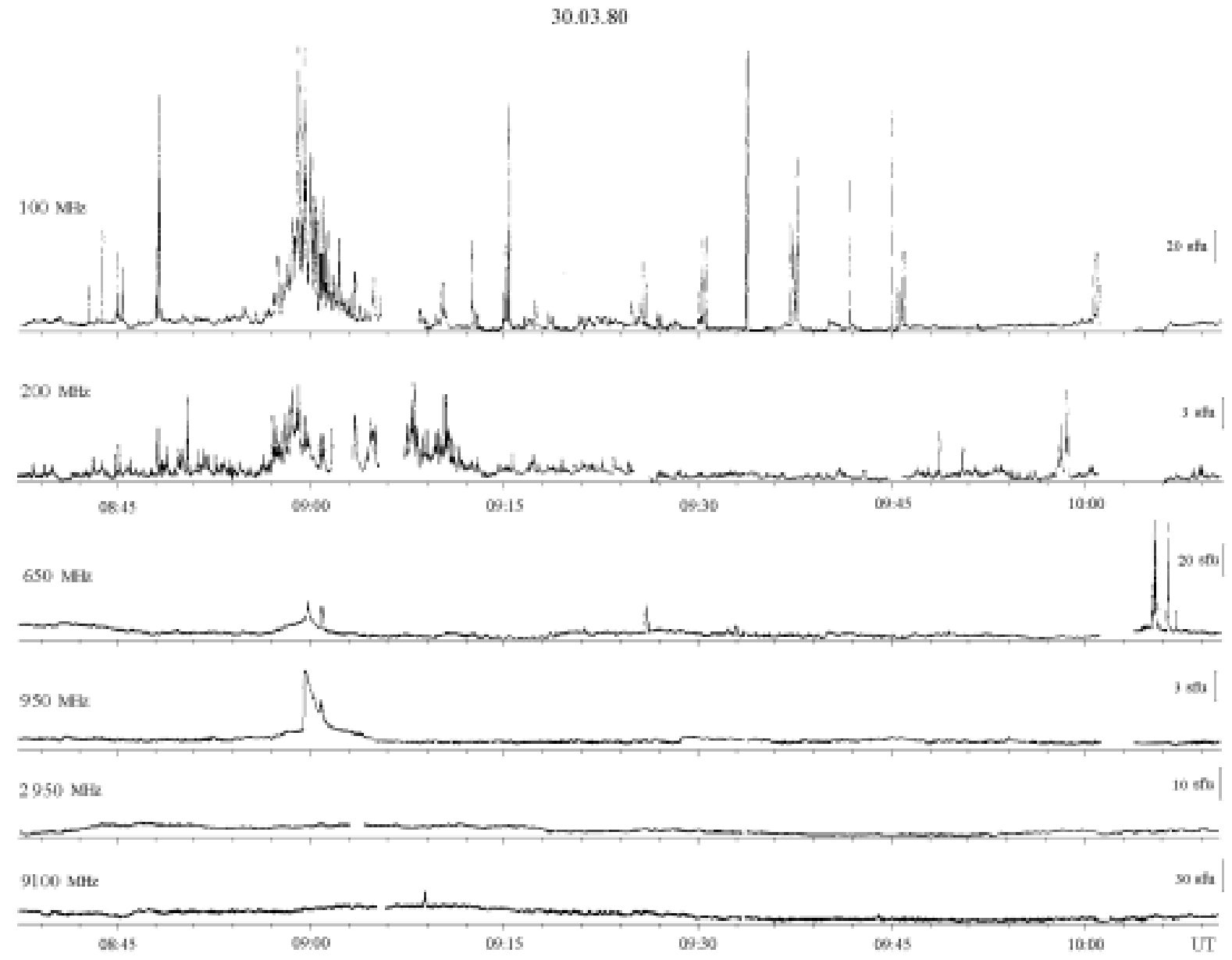

Fig. 6. Temporal behavior of solar radio emission before the occurrence of a CME. The CME was registered at 10:33 UT on 30/03/1980 by the coronagraph onboard the SMM spacecraft.

cyclic recurrences of solar activity and the shift of the center of masses of solar system bodies" is presented in Fig. 5 .

Levin Alexander - after training program - student of Moscow Physics-Technical Institute. In the work "A study of the influence of scattering in the solar corona on the time characteristics of microwave burst pulses" he discovered that the form of pulses change and their time duration increase during their passage through the scattering layer. The comparison of simulations and experimental data allows to infer conclusions about the scattering layer in the solar corona.

Ergle Sergey, student of Nizhny-Novgorod Technical University -"Study of the relation between the parameters of 


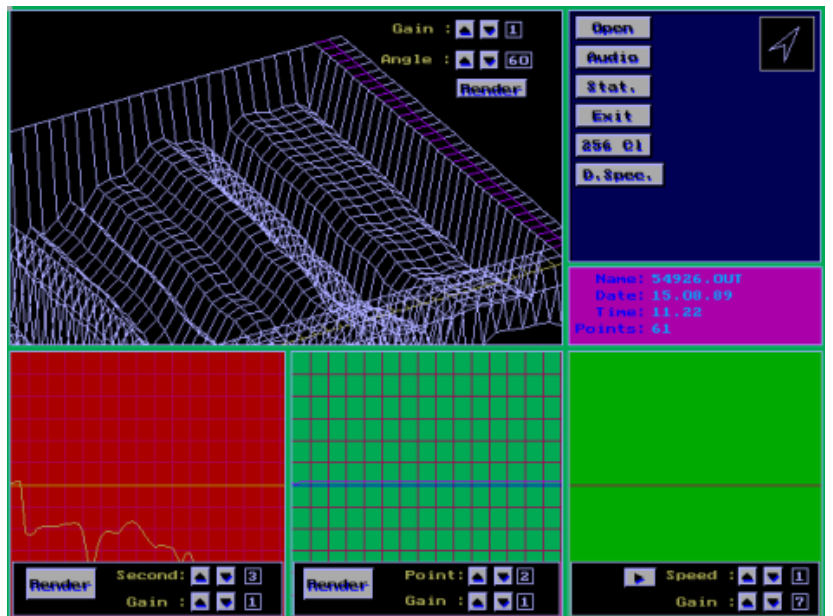

Fig. 7. The example of presentation the results of spectral data treatment.

Coronal Mass Ejections (CMEs) that are not accompanied by optical flares and the characteristics of solar radioemission". Original recordings of solar radio emission obtained by the Radio Astronomical Observatory "Zimenki" at six frequencies in the range of $9100-100 \mathrm{MHz}$ were used for the study. Sporadic emission of various phenomena such as simple impulsive $\mathrm{C}$ bursts, simultaneous recordings at numerous frequencies, noise storms and their variations decreasing in magnitude, all reflect processes in the lower layers of the solar atmosphere during the period preceding a CME onset (see Fig. 6).

\subsection{Further work}

Students who decide to continue working in NIRFI related subjects perform more detailed works at higher scientific levels during their final year courses within the framework of grants and projects of the institute. In this case the students who passed the preliminary stages of instruction as schoolchildren, are immediately active as they can effectively use the knowledge, obtained by them at Institutes of Higher Education.

Such works can be demonstrated based on the following examples.

Grechin Sergey - "The development of a method for the primary study of short-term changes in solar activity". He developed the special program for the treatment of our spectral data (sweeping spectrograph in 14-17 GHz) - the example of it is presented on Fig. 7: we can see plane and 3-D image.

Using this program the phenomena preceding the CME formation and flare activity are studied more effectively. Figure 8 represents samples of the existence of fast changes in the temporal behavior of radio emission during the observations. They are characterized by a consistent origin of narrow-band $(1-1.5 \mathrm{GHz})$ components of emission, moving from low to high frequencies in 2-4 s, that means that the ve-
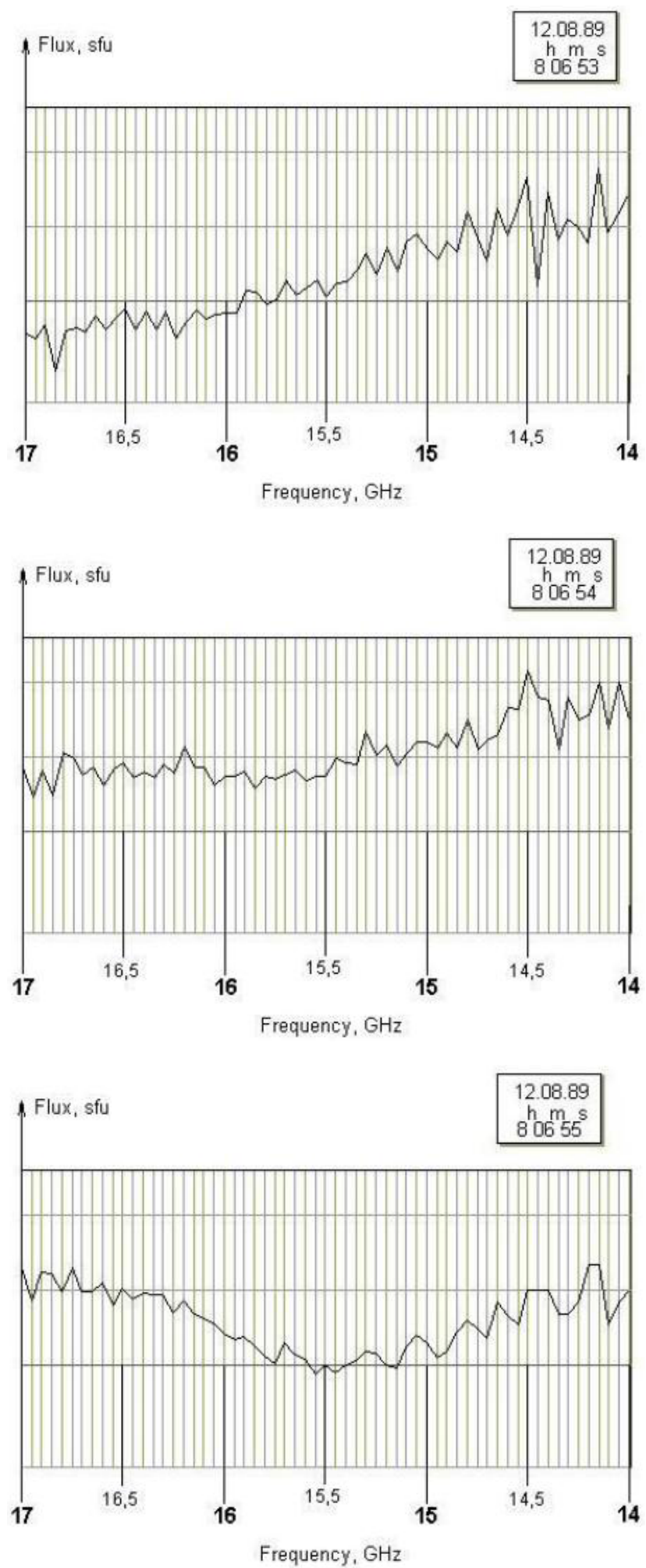

Fig. 8. Microwave solar radio emission spectra of solar flare (12/08/1989, 08:06:53 (a), 08:06:54 (b), and 08:06:55 (c) UT), time resolution is one second.

locity value is about $1-4 \mathrm{GHz} / \mathrm{s}$. The closer the time of $\mathrm{CME}$ registration, the higher the emission flux magnitude. 


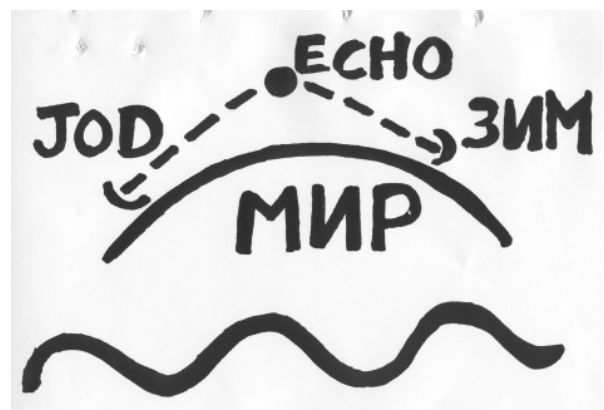

Fig. 9. Illustration of the first international experiment on space communication. The signal communicated was "MIR" that in Russian means "peace".

Zyryanova Marina - "Some questions concerning the analysis of the cyclic activity of the Sun using radio data: 11-year cycle and extended forecasts of solar activity in radio emission".

Zhernokletov Alexey - "Simulation of a radar signal reflected from the solar corona".

In this stage continues the participation of students in the seminars and the conferences no longer only as the listeners, but also as the participants. The large group of students participated in the conference of the NIS and Baltic States countries on "Physics of the solar and star activity" and Summer School, organized and carried out in NIRFI during June 2003.

\section{Outreach efforts for the Institute's achievements}

A substantial number of NIRFI's senior staff combines scientific work with pedagogical activities, in which results obtained at the institute within the framework of scientific activities, are included. Such examples include: "Emission of electromagnetic waves", "Technical methods of diagnostic studies" and "Electromagnetic fields and vital activity".
The colleagues of NIRFI regularly appear in the press and on the television, commenting on the newest scientific achievements, and also on space phenomena, which generates lively public interest.

This practice began already during the first years of the institute's existence, when the first international experiment on space communication with the participation of USA, England and the Soviet Union (USSR) was conducted. NIRFI, a participant in the experiment from the USSR, carried out the reception of the signal, radiated from Jodrell Bank (UK) to the passive communications relay, reflected by the communication satellite (USA), see Fig. 9.

\section{Conclusion}

In conclusion, both education and training of the next generation and regional outreach efforts for latest scientific achievements and results, are an integral part in the routine scientific work of NIRFI. Most of the students, who participate in the NIRFI programs for familiarizing them with space and SunEarth physics phenomena, elect to continue their education in the natural-sciences and engineering specialties. And even those, who select other careers, continue to maintain contacts with their teachers at NIRFI and note that the period of their life they spent familiarizing themselves with the joy of research work in the fields of space physics and geophysics, left a lasting imprint on their formation in a global view.

Acknowledgements. The authors thank their colleagues for continuing support and discussion. This work is carried out with the support of Russian Fund for Basic Research (Grant 03-02-16691), Ministry of Education (grant E02-11.0-27) and FPSTP (Astronomy). The authors thank S. S. Limaye and N. Crosby for assisting in evaluating and editing this paper.

Edited by: R. Pertzborn

Reviewed by: S. Limaye and N. Crosby 